\title{
Optimizing reactive ion etching to remove sub-surface polishing damage on diamond
}

Cite as: J. Appl. Phys. 125, 244502 (2019); https://doi.org/10.1063/1.5094751

Submitted: 05 March 2019 . Accepted: 04 June 2019 . Published Online: 28 June 2019

Marie-Laure Hicks, Alexander C. Pakpour-Tabrizi, Verena Zuerbig, Lutz Kirste, Christoph Nebel, and Richard B. Jackman (iD)
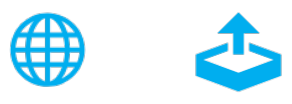

\section{ARTICLES YOU MAY BE INTERESTED IN}

Roughness dependent wettability of sputtered copper thin films: The effect of the local surface slope

Journal of Applied Physics 125, 244307 (2019); https://doi.org/10.1063/1.5092672

Optimized waveguide coupling of an integrated III-V nanowire laser on silicon Journal of Applied Physics 125, 243102 (2019); https://doi.org/10.1063/1.5097405

Charge collection efficiency in photoconductive detectors under small to large signals Journal of Applied Physics 125, 244503 (2019); https://doi.org/10.1063/1.5096900

\section{ri AlluXa rouroorical COATING PARTNER}




\title{
Optimizing reactive ion etching to remove sub-surface polishing damage on diamond
}

\author{
Cite as: J. Appl. Phys. 125, 244502 (2019); doi: 10.1063/1.5094751 \\ Submitted: 5 March 2019 . Accepted: 4 June 2019 . \\ Published Online: 28 June 2019
}

Marie-Laure Hicks, ${ }^{7}$ Alexander C. Pakpour-Tabrizi,, ${ }^{7}$ Verena Zuerbig, ${ }^{2}$ Lutz Kirste, ${ }^{2}$ Christoph Nebel, ${ }^{2}$ and Richard B. Jackman ${ }^{1, a)}$ (D)

\author{
AFFILIATIONS \\ ${ }^{1}$ London Centre for Nanotechnology and Department of Electronic and Electrical Engineering, University College London, \\ 17-19 Gordon Street, London WC1H OAH, United Kingdom \\ ${ }^{2}$ Fraunhofer Institute for Applied Solid State Physics IAF, Tullastrasse 72, 79108 Freiburg, Germany
}

${ }^{a)}$ Author to whom correspondence should be addressed: r.jackman@ucl.ac.uk

\begin{abstract}
Low defect smooth substrates are essential to achieve high quality diamond epitaxial growth and high performance devices. The optimization of the $\mathrm{Ar} / \mathrm{O}_{2} / \mathrm{CF}_{4}$ reactive ion etching (RIE) plasma treatment for diamond substrate smoothing and its effectiveness to remove subsurface polishing damage are characterized. An $\mathrm{O}_{2} / \mathrm{CF}_{4}$ RIE process and the effect of different process parameters (inductively coupled plasma, platen power, and pressure) were initially examined. This process, however, still produced a detrimental effect to surface roughness, with etch pits across the surface of the sample. The addition of argon to the process achieved near-zero surface pit density and reduced roughness by $20 \%-44 \%$ after 6 and $10 \mu \mathrm{m}$ etching. Iterative high-resolution X-ray diffraction measurements provided a nondestructive tool to examine the effectiveness of polishing damage removal and in this case reduced after removal of $6 \mu \mathrm{m}$ of material from the surface of the diamond substrate with the smoothing treatment.
\end{abstract}

Published under license by AIP Publishing. https://doi.org/10.1063/1.5094751

\section{INTRODUCTION}

Diamond is a material with exceptional properties, showing promise for a diverse range of technical applications, such as power electronics, quantum technologies, and biotechnology. ${ }^{1-5}$ High quality epitaxial diamond growth is reliant on low defect smooth substrates; this is crucial to successfully produce high performing diamond devices.

Two categories of defects can pose a challenge to achieving high quality epitaxy: bulk defects inherent to the substrate material and polishing-induced damage. The latter is introduced during the polishing and smoothing of diamond substrates in the form of pits and dislocations. The polishing process, most commonly scaife polishing, relies on a mechanical friction-based process to remove materials from the surface. ${ }^{6}$ Dislocations introduced by this process are able to propagate during epitaxial growth into the newly formed material and are extremely detrimental to device performance as they degrade carrier transport and lifetimes. ${ }^{7,8}$ Novel low-damage polishing methods are being developed but are not currently widely used. ${ }^{9,10}$
Polishing damage is thought to extend under the processed surface of the diamond substrate into the near-surface/bulk region. A few estimates or precise assessments are reported to date and those that range from hundreds of nanometers up to $10 \mu \mathrm{m}$ of polishing-induced damage in the material. ${ }^{71-13}$ Surface plasma treatments before epitaxial growth have, therefore, been suggested as a method of removing this damaged region to improve the quality of the substrate and minimize defect propagation during epitaxial growth. Such an optimal treatment must fulfill a number of requirements: efficient material removal rate, polishing damage reduction (rather than simply replacing it with further damage), and surface roughness maintenance or ideally reduction.

Among the range of techniques available to remove materials from a surface, reactive ion etching (RIE), or better, inductively coupled plasma (ICP) RIE, are suggested as the most suitable methods available. The use of ICP RIE enables the ion densities in the plasma to be decoupled from the applied RF plasma power, adding a useful extra experimental parameter for process optimization and is the form of RIE used in this work. A wide range of RIE gas mixtures has been reported in the literature with varying 
success with regard to the achieved surface quality. ${ }^{7,14-17}$ Only a few, using $\mathrm{Ar} / \mathrm{O}_{2}, \mathrm{Ar} / \mathrm{Cl}_{2}$, or $\mathrm{CF}_{4} / \mathrm{O}_{2}$, reported a reduction in surface roughness. ${ }^{18-21} \mathrm{Ar} / \mathrm{Cl}_{2}$ offered the largest smoothing effect; however, the etch rate was slower than that for $\mathrm{CF}_{4} / \mathrm{O}_{2}$, and the measurements were achieved on samples with very low starting roughness. As such, in the work reported here, the plasma process from Ando et al. was taken as the most promising starting point for the purpose of further process development. ${ }^{18}$

Initially, a $\mathrm{CF}_{4} / \mathrm{O}_{2}$ plasma was optimized to impart minimal etch pit density and roughness change to the surfaces of (100) single crystal diamond substrates. Argon was added to the process gases to address the remaining surface roughening issues and achieve a surface smoothing effect. The removal of subsurface polishing damage was then probed with the aid of the high resolution X-ray diffraction (HRXRD) characterization method. Previously, the effectiveness of polishing damage removal on diamond was characterized through epilayer growth and device fabrication. ${ }^{13,21,22}$ HRXRD was performed here after repeated etching steps had removed materials from the surface. This technique has been reported in the literature to study polishing damage in silicon carbide ${ }^{23}$ and was applied here to determine the effectiveness of the RIE process and estimate the extent of the polishing damage (as a function of depth). This approach offers a nondestructive qualitative assessment of polishing damage depth on diamond substrates. The substrates can be iteratively processed to reveal a complete picture of the depth of the damage present in a given sample set, relative to initial quality. This also enabled the precise evaluation of the effectiveness of $\mathrm{Ar} / \mathrm{O}_{2} / \mathrm{CF}_{4}$ plasma for diamond substrate preparation.

\section{EXPERIMENTAL}

The effects of different plasma parameters were probed to determine an optimal ICP RIE treatment for diamond surface smoothing. All substrates were synthetic $4 \times 4 \mathrm{~mm}^{2}$ (100) Sumitomo type Ib substrates characterized with atomic force microscopy (AFM-Bruker Dimension ICON) prior to and after processing. The samples were mechanically polished by the manufacturer, with characteristic lines and striations of scaife polishing observed in AFM scans. Roughness measurements presented throughout this work are a mean of the roughness measured across five $20 \times 20 \mu \mathrm{m}^{2}$ scans and its standard deviation to provide a representative value and range for the sample.

The effect of ICP power and platen power was initially examined by treating each sample with ICP power set to 200, 300, and $400 \mathrm{~W}$ and $100 \mathrm{~W}$ or $200 \mathrm{~W}$ of platen power. Other process parameters were fixed, at $26 \mathrm{sccm} \mathrm{O}_{2}$ and $4 \mathrm{sccm} \mathrm{CF}_{4}$ at $10 \mathrm{mTorr}$ for $15 \mathrm{~min}$. The four least roughened samples were then processed with the same gas parameters and fixed ICP power at $400 \mathrm{~W}$, platen power at $100 \mathrm{~W}$ while the pressure was varied from 5 mTorr to 10,15 , and $20 \mathrm{mTorr}$, respectively, for $15 \mathrm{~min}$.
Treatment OC (Table I) was determined following the examination of ICP RIE $\mathrm{O}_{2} / \mathrm{CF}_{4}$ parameter effects on the surface of the processed substrates. Repeatability was tested by processing a new substrate to remove $5 \mu \mathrm{m}$ from the surface and its effects were examined with AFM and scanning electron microscopy (SEM).

Treatment AOC (Table I) included the addition of argon into the gas mix. A new substrate was processed to remove $3.2 \mu \mathrm{m}$ from the surface and examined with AFM and SEM. Repeatability of the effects of $\mathrm{Ar} / \mathrm{O}_{2} / \mathrm{CF}_{4}$ was tested across seven samples.

The etch rate of the different treatments was determined as the slope of measured etch depth against etch time. A $300 \mu \mathrm{m}$ thick polycrystalline diamond shadow mask was used to block etching in certain regions during ICP RIE processing, and etch depth was measured with a Dektak Stylus Profilometer. The etch depths achieved on samples were extrapolated from the linear etch rate. All plasma treatments were done in an STS multiplex pro-inductively coupled deep reactive ion etcher with samples mounted on a ceramic wafer and back-cooled to $20^{\circ} \mathrm{C}$.

The effect of treatment AOC on crystal quality and polishing damage was examined with high resolution X-ray diffraction (PANALYTICAL X'pert Pro Materials Research Diffractometer). $\mathrm{X}$-ray and AFM measurements were performed on a given substrate (GD07-5D) after $0.5 \mu \mathrm{m}, 1 \mu \mathrm{m}, 2 \mu \mathrm{m}, 4 \mu \mathrm{m}, 6 \mu \mathrm{m}$, and $8 \mu \mathrm{m}$ $\mathrm{Ar} / \mathrm{O}_{2} / \mathrm{CF}_{4}$ ICP RIE.

\section{RESULTS}

\section{A. $\mathrm{O}_{2} / \mathrm{CF}_{4}$ and $\mathrm{Ar} / \mathrm{O}_{2} / \mathrm{CF}_{4}$ ICP RIE optimization}

The mean roughness of the as-received polished samples used here for plasma optimization ranged between 1.32 and $2.62 \mathrm{~nm}$. Their roughness was subsequently measured after the $\mathrm{O}_{2} / \mathrm{CF}_{4}$ treatment with a range of ICP and platen power settings (Figs. 1 and 2). It is apparent that ICP power had a minimal effect on surface roughness; measured roughness was within the standard deviation of the as-received roughness values (Fig. 1). In contrast, doubling the platen power from $100 \mathrm{~W}$ to $200 \mathrm{~W}$ increased the surface roughness by $50 \%-100 \%$ (Fig. 2). This roughness increase likely corresponded to the formation of pits across the surface, with a higher pit density and depth observed in samples processed at 200 $\mathrm{W}$ platen power compared to $100 \mathrm{~W}$, as illustrated in AFM images typical for regions across both surfaces in Fig. 3.

Surface roughness was also observed to increase with increasing process pressure (Fig. 4). The sample processed at 5 mTorr was the only sample whose roughness remained within the standard deviation of average roughness measured prior to etching. Again, roughening of the surface correlated with the formation of etch pits across the surface, appearing to align along the striation marks left by the original polishing process (Fig. 5).

TABLE I. Process parameters for treatments OC and AOC.

\begin{tabular}{lccccccc}
\hline \hline Treatment & $\mathrm{Ar}(\mathrm{sccm})$ & $\mathrm{O}_{2}(\mathrm{sccm})$ & $\mathrm{CF}_{4}(\mathrm{sccm})$ & $\mathrm{ICP}(\mathrm{W})$ & Platen $(\mathrm{W})$ & Pressure $(\mathrm{mTorr})$ & Etch rate $(\mathrm{nm} / \mathrm{min})$ \\
\hline OC & $\ldots$ & 26 & 4 & 400 & 100 & 5 & 60.5 \\
AOC & 100 & 11 & 4 & 250 & 300 & 5 & 61.5 \\
\hline \hline
\end{tabular}




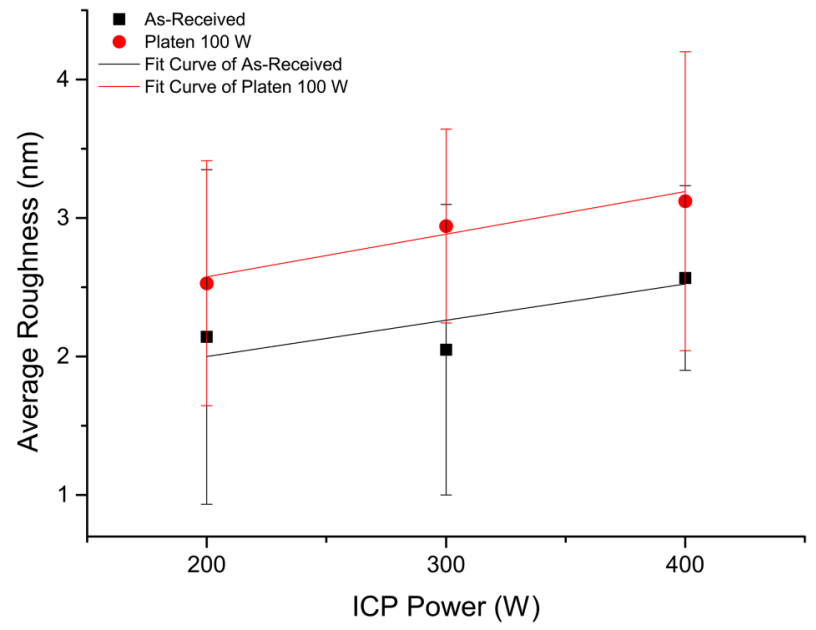

FIG. 1. Effect of ICP power on surface roughness at $100 \mathrm{~W}$ platen power with $\mathrm{O}_{2} / \mathrm{CF}_{4}$. The average roughness of the samples after plasma treatment is within the standard deviation range of the as-received roughness measurements.

Observations of the effect of the power and pressure settings were used to define the optimized process labeled treatment OC. It was subsequently characterized, and its effect over a longer etch time was examined. After a $5 \mu \mathrm{m}$ deep etch, the average roughness of the sample had increased from $3.33 \mathrm{~nm}$ to $4.56 \mathrm{~nm}$. The observations of little change in roughness on previous samples were not reproduced, and aligned etch pits were found across the surface of the sample (Fig. 6). The etch rate was measured to be $60 \mathrm{~nm} / \mathrm{min}$.

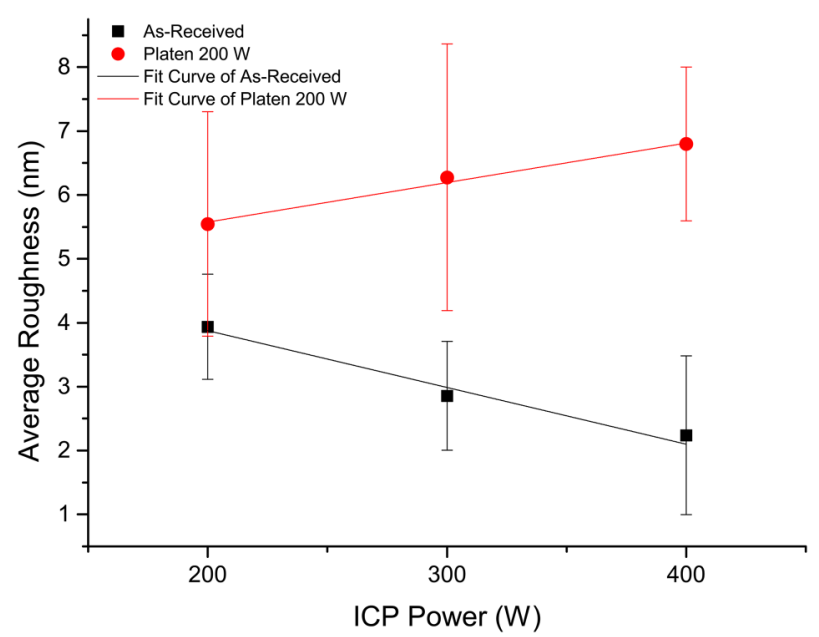

FIG. 2. Effect of ICP power on surface roughness at $200 \mathrm{~W}$ platen power with $\mathrm{O}_{2} / \mathrm{CF}_{4}$. The average roughness of the samples in this case increases significantly, between $50 \%$ and $100 \%$ compared to the as-received.

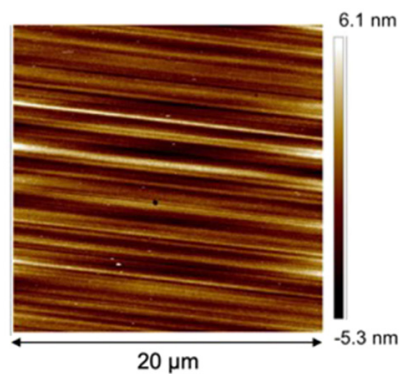

(a) ICP $400 \mathrm{~W}$, Platen $100 \mathrm{~W}$ $R_{a}=2.1 \mathrm{~nm}$ from $1.8 \mathrm{~nm}$

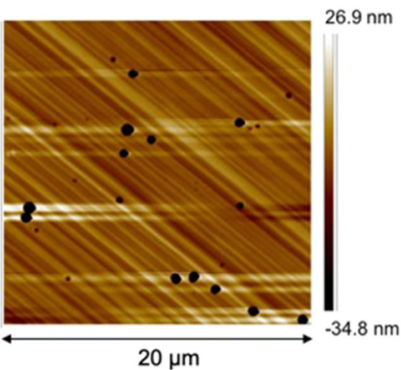

(b) ICP $400 \mathrm{~W}$, Platen $200 \mathrm{~W}$ $\mathrm{R}_{\mathrm{a}}=3.7 \mathrm{~nm}$ from $1.7 \mathrm{~nm}$
FIG. 3. Comparison of the surface of samples by AFM $\left(20 \times 20 \mu \mathrm{m}^{2}\right.$ scans $)$, processed at (a) $100 \mathrm{~W}$ platen power (b) and $200 \mathrm{~W}$ platen power with $\mathrm{O}_{2} / \mathrm{CF}_{4}$. The surface roughness increased by 50\%-100 \% compared to as-received measurements with higher platen power, most likely due to the formation of deep etch pits (black circular features) across the surface. Parallel lines across the surface are striations from the original polishing process.

The process was modified to include argon into the gas mix (treatment AOC). In this case, after a $3.2 \mu \mathrm{m}$ etch, the average surface roughness of the sample was reduced from $3.9 \mathrm{~nm}$ to $2.4 \mathrm{~nm}$ (Fig. 7). AFM and SEM observations revealed extremely sparse near-to-zero surface pit density. Repeats of this process produced a further smoothing effect with reductions in surface roughness between $20 \%$ and $44 \%$ relative to the as-received roughness on four substrates after $6-10 \mu \mathrm{m}$ etch. Three substrates presented roughness increases of 4.5 and $78 \%$ after $6 \mu \mathrm{m}$ and $43 \%$ after $10 \mu \mathrm{m}$ etch, respectively. The etch rate of the treatment AOC was determined to be $62 \mathrm{~nm} / \mathrm{min}$.

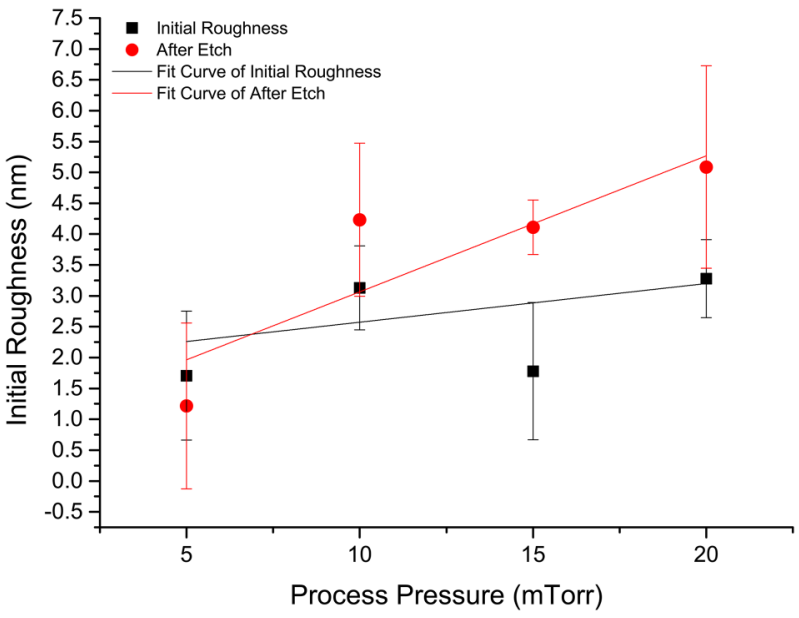

FIG. 4. Effect of process pressure on surface roughness at $400 \mathrm{~W}$ ICP power and $100 \mathrm{~W}$ platen power with $\mathrm{O}_{2} / \mathrm{CF}_{4}$. The average roughness increased to a larger extent at higher pressures, whereas no change in roughness was observed at $5 \mathrm{mTorr}$. 


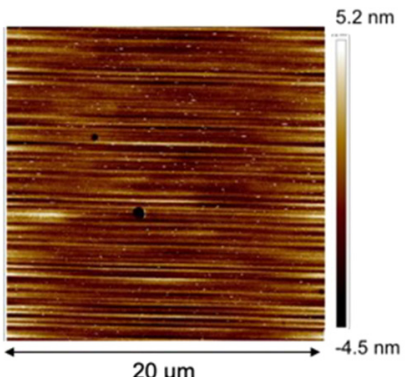

$20 \mu \mathrm{m}$

(a) Pressure 5 mTorr $R_{a}=1.2 \mathrm{~nm}$ from $1.7 \mathrm{~nm}$

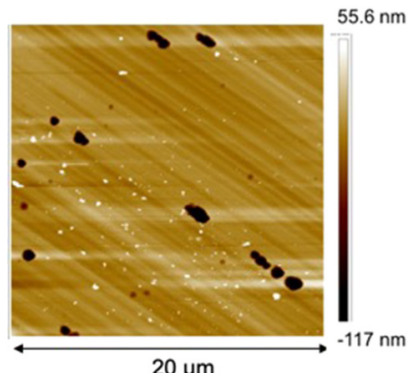

$20 \mu \mathrm{m}$

(b) Pressure $10 \mathrm{mTorr}$ $R_{\mathrm{a}}=5.0 \mathrm{~nm}$ from $3.2 \mathrm{~nm}$
FIG. 5. Comparison of the surface of samples processed with AFM $\left(20 \times 20 \mu \mathrm{m}^{2}\right.$ scans) at (a) $5 \mathrm{mTorr}$ and (b) $10 \mathrm{mTorr}$. The surface roughness increased with increasing pressure, most likely due to the formation of deep etch pits across the surface. The etch pits were aligned along the polishing marks, with some beginning to merge into larger, deeper etch pits.

\section{B. Characterization of polishing damage removal}

The roughness of a given sample (GD07-5D), etched iteratively with treatment AOC was then characterized with AFM, showing a reduction overall as it was etched down to $8 \mu \mathrm{m}$ (Fig. 8).

Figure 9 presents the reciprocal space map for (004) and (113) as-received after polishing and after $4 \mu \mathrm{m}$ and $6 \mu \mathrm{m}$ were removed with treatment AOC on substrate GD07-5D. After observing no significant change after each previous etch, the diffuse scattering at the tails of the peaks reduced significantly after the $6 \mu \mathrm{m}$ etch. Additionally, no change was observed to the full width half maximum, as the bulk crystal quality remained unaffected by the treatment.

\section{DISCUSSION}

ICP RIE etching clearly offers a large degree of tunability to the plasma etching process to achieve a treatment for diamond substrates

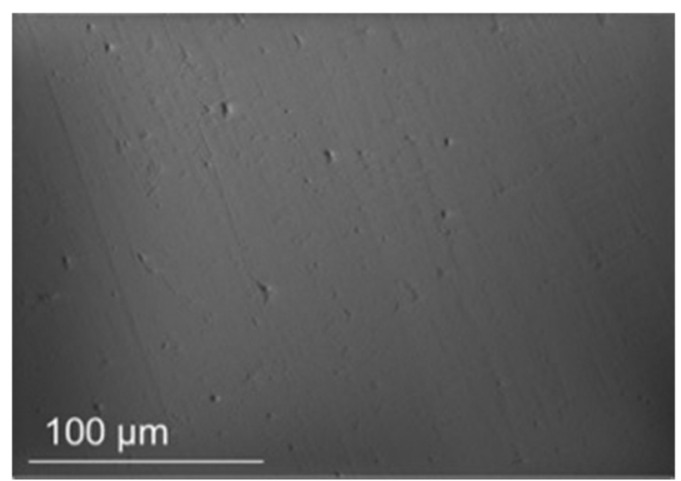

FIG. 6. Effect of the treatment $\mathrm{OC}$ on the sample surface after $5 \mu \mathrm{m}$ etch (SEM). Etch pits and defects are observed across the surface, aligned with the polishing marks.

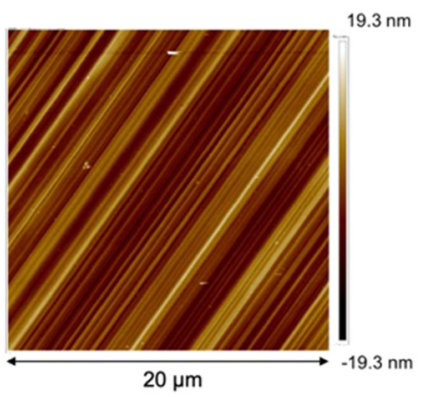

(a) As-received

$\mathrm{R}_{\mathrm{a}}=3.9 \mathrm{~nm}$

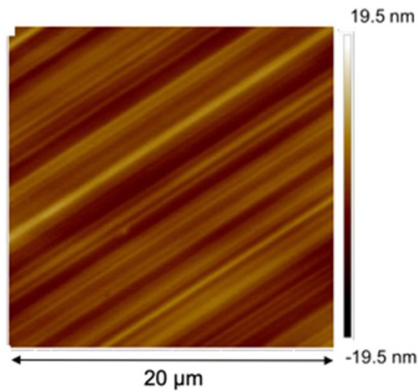

(b) After Etch $(3.2 \mu \mathrm{m})$ $\mathrm{R}_{\mathrm{a}}=2.4 \mathrm{~nm}$
FIG. 7. Effect of treatment $A O C$ on the sample surface, a comparison between (a) as-received and (b) after $3.2 \mu \mathrm{m}$ etch (AFM, $20 \times 20 \mu \mathrm{m}^{2}$ scans). The surface is similar to the as-received surface with no formation of etch pits and reduction in surface roughness.

with a reasonable etch rate while minimizing any damage or roughening of the surface.

The $\mathrm{O}_{2} / \mathrm{CF}_{4}$-based process, treatment $\mathrm{OC}$, etched the diamond via a predominantly chemical process. Oxygen ions are able to oxidize and break the carbon bond, removing atoms from the surface of the sample. The fluorine ions are also highly reactive and enhance this process. The presence of fluorine was considered essential to avoid any effect from contamination present in the etching chamber, silicon, in particular, which is known to cause micromasking on diamond. ${ }^{18,2}$

The downside of the chemical nature of the etch was the preferential etching of defective areas of the diamond surface by

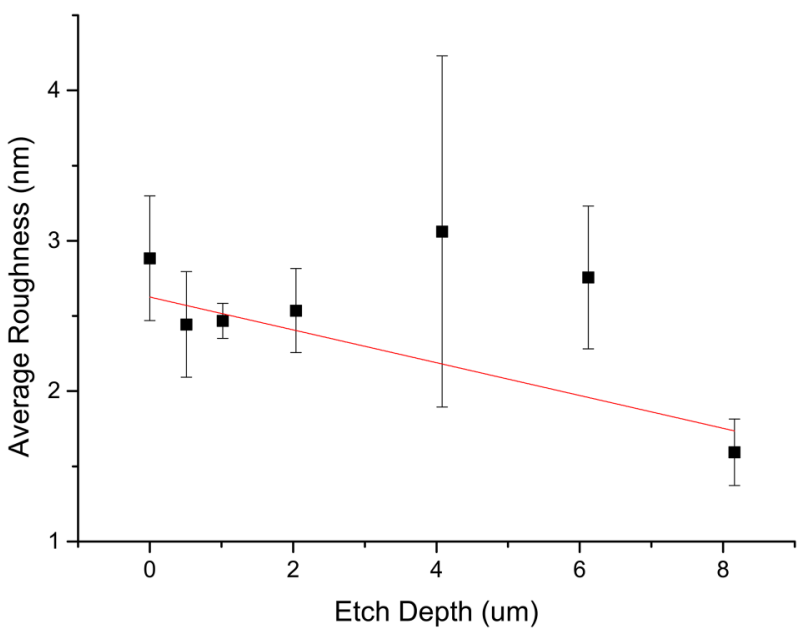

FIG. 8. Average surface roughness of a given sample (GD07-5D) depending on etch depth with treatment AOC. The surface roughness followed a trend in reduction as the plasma process was used to remove increasing thicknesses of the material from the surface. 
(a) As-received
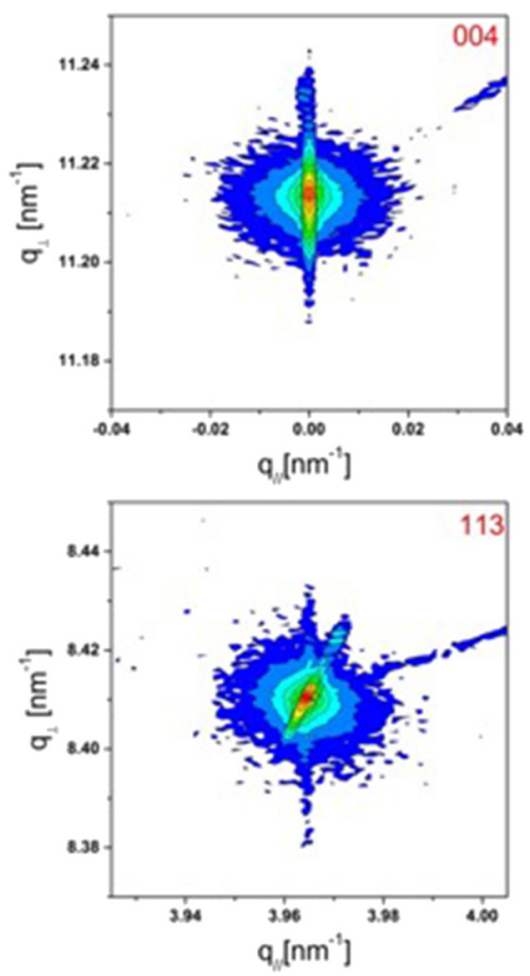

(b) After $4 \mu \mathrm{m}$ etch
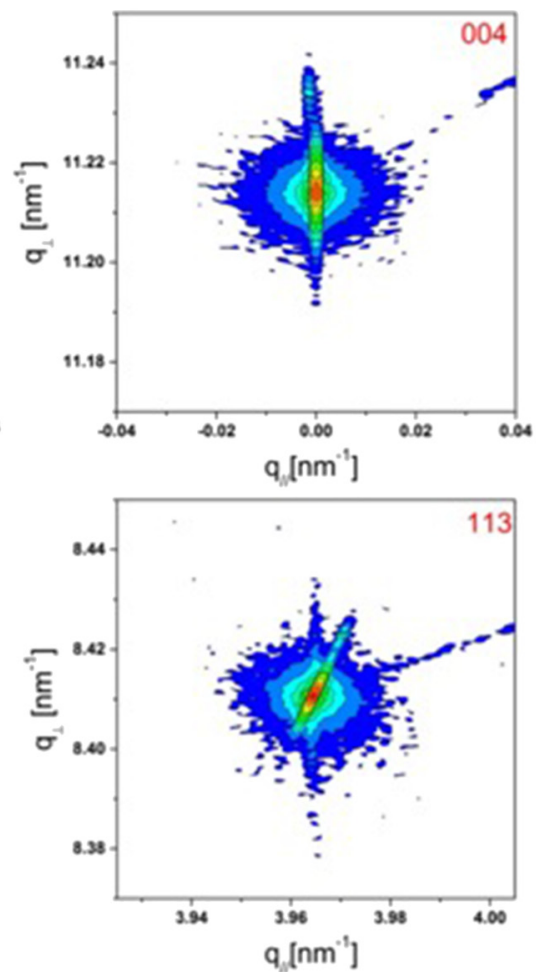

(c) After $6 \mu \mathrm{m}$ etch
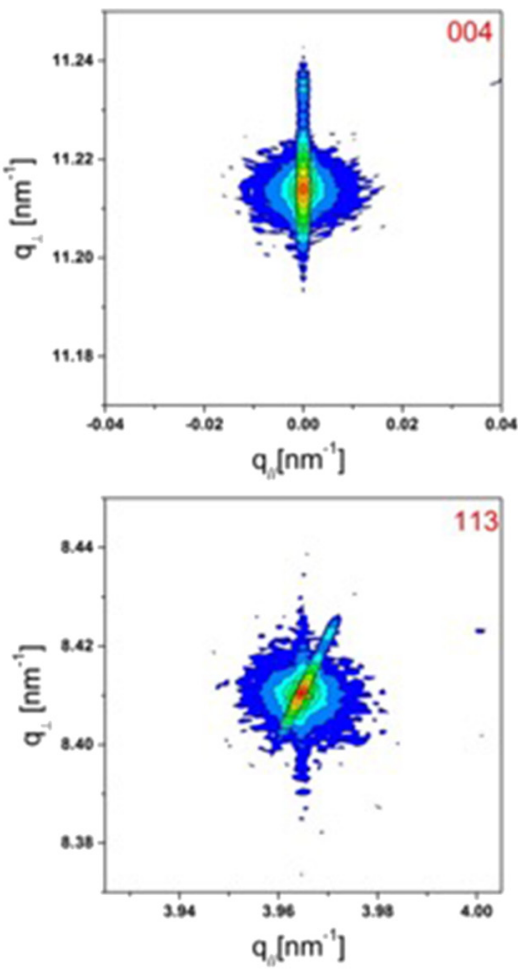

FIG. 9. Reciprocal space mapping with HRXRD: comparison between (a) as-received, (b) after $4 \mu \mathrm{m}$ etch, and (c) after $6 \mu \mathrm{m}$ etch (b) for (004) and (113). The diffuse scattering remained unchanged between (a) and (b) and reduced following treatment AOC to $6 \mu \mathrm{m}$ depth.

oxygen ions. Well-documented in the literature as a method for revealing defect sites for surface defect analysis, this was likely the mechanism at play in the formation of etch pits across the surface of the samples. Here, polishing defects were particularly highlighted where the pits lined up with polishing lines observed with both AFM and SEM. ${ }^{25-29}$

The effect of changing ICP power, platen power, and pressure was examined to establish an etch process, minimizing the preferential etching of such defects by oxygen to maintain the as-received surface roughness. The ICP power controls the ion density in the plasma, which appeared to have very little effect on the surface roughness of etched samples as shown in Fig. 1. As such, it was maximized to boost the etch rate, directly proportional to ICP power.

On the other hand, platen power, determining the bombardment energy of the ions in the plasma, had a strong impact on sample surface roughness (Figs. 2 and 3). An explanation would be that increasing the bombardment energy increases the energy of oxygen ions at the surface of the sample and enhances the preferential chemical etching of defects. Minimal platen power was preferred for the chemical process.

A low process pressure also resulted in smoother etching of diamond. The process pressure determines the amount of reactive species available to etch the sample. An increase in reactive species could explain the increase in observed preferential etching of defects (Figs. 4 and 5).

The chemical nature of treatment OC, however, posed the problem of sample dependence and repeatability given that surface defect density varies between substrates. Even after optimization, preferential etching of defective areas still occurred. The bulk and polishing defect density may also vary across samples. The etch recipe developed may, therefore, smooth a sample with a low or average defect density but when applied to a sample with worse polishing damage, preferential etching of defects will increase the surface roughness. This supports the different observations made after the $5 \mu \mathrm{m}$ etch (Fig. 6) and also raised the question of comparability between different samples for such a process optimization.

Following these findings, argon was introduced into the gas mix to change the nature of the etch process by adding a physical mechanism to the otherwise chemically promoted processes. ${ }^{19}$ In treatment AOC, argon is the primary active etching species, similar to an ion milling process with ions impacting the surface and physically breaking bonds. Oxygen ions gained a new role as ions reacting with the carbon atom by-products of the milling and removing them from near the surface by forming $\mathrm{CO}$ or $\mathrm{CO}_{2}$. 
The power settings were modified to accommodate for the change in the etch mechanism and to ensure that the ion milling was not too aggressive and maintain a smooth surface. Previously reported etching work by the authors using $\mathrm{Ar} / \mathrm{O}_{2}$ ICP RIE for device fabrication highlighted the potential problem of an aggressive plasma with high ICP power at $500 \mathrm{~W}$ and a platen power of $200 \mathrm{~W}$ forming craterlike features on the surface. ${ }^{30}$ Reduced ion density and maximized bombardment energy was hence considered important when defining treatment AOC.

The physical nature and properties of treatment AOC successfully removed materials from the surface of the sample, while reducing surface roughness, and importantly, with repeatability to etch depths up to $10 \mu \mathrm{m}$.

Finally, HRXRD characterization showed the effectiveness of treatment AOC at removing subsurface polishing damage, as indicated by the observed change in diffuse scattering presented in Fig. 9. This was a novel nondestructive validation for a plasma treatment on (100) single crystal diamond substrates with regard to successful removal of polishing damage. The use of this method took away the need for destructive epitaxial growth or device fabrication to determine polishing damage reduction and could be a quality control method for high quality epitaxy and devices. In addition, it offered an estimate of the depth of polishing damage: beyond $6 \mu \mathrm{m}$ in the case of the examined sample. Further work repeating this iterative characterization on multiple substrates could provide an average depth of polishing damage on diamond substrate sets.

\section{CONCLUSION}

In conclusion, an $\mathrm{Ar} / \mathrm{O}_{2} / \mathrm{CF}_{4}$ ICP RIE process has been developed for use on (100) single crystal diamond substrates. It successfully produced repeatable, smooth, pit-free surfaces and was shown to reduce subsurface polishing damage. The use of an iterative etch-HRXRD characterization process is suggested as a nondestructive protocol to determine an average polishing damage removal and depth, values of importance to fully harness the opportunities offered by the exceptional properties of diamond.

\section{ACKNOWLEDGMENTS}

This work was funded by the European Commission project “GREENDIAMOND," H2020 Large Project (No. SEP-210184415), and the UK's Engineering and Physical Research Council (EPSRC) (No. EP/H020055/1). One of us (M.-L. Hicks) also thanks the EPSRC for the award of a Ph.D. studentship.

\section{REFERENCES}

${ }^{1}$ R. Schirhagl, K. Chang, M. Loretz, and C. L. Degen, "Nitrogen-vacancy centers in diamond: Nanoscale sensors for physics and biology," Annu. Rev. Phys. Chem. 65, 83-105 (2014).

${ }^{\mathbf{2}}$ L. Childress and R. Hanson, "Diamond NV centers for quantum computing and quantum networks," MRS Bull. 38, 134-138 (2013).

${ }^{3}$ C. J. H. Wort and R. S. Balmer, "Diamond as an electronic material," Mater. Today 11, 22-28 (2008).

${ }^{4} \mathrm{H}$. Umezawa, "Recent advances in diamond power semiconductor devices," Mater. Sci. Semicond. Process. 78, 147-156 (2018).
${ }^{5}$ P. A. Nistor, P. W. May, F. Tamagnini, A. D. Randall, and M. A. Caldwell, "Long-term culture of pluripotent stem-cell-derived human neurons on diamond-A substrate for neurodegeneration research and therapy," Biomaterials 61, 139-149 (2015).

6J. R. Hird and J. E. Field, “Diamond polishing," Proc. R. Soc. A 460, 3547-3568 (2004).

${ }^{7}$ I. Friel, S. L. Clewes, H. K. Dhillon, N. Perkins, D. J. Twitchen, and G. A. Scarsbrook, "Control of surface and bulk crystalline quality in single crystal diamond grown by chemical vapour deposition," Diam. Relat. Mater. 18, 808-815 (2009).

${ }^{8}$ T. Schuelke and T. A. Grotjohn, "Diamond polishing," Diam. Relat. Mater. 32, 17-26 (2013).

${ }^{9}$ E. L. H. Thomas, G. W. Nelson, S. Mandal, J. S. Foord, and O. A. Williams, "Chemical mechanical polishing of thin film diamond," Carbon 68, 473-479 (2014); preprint arXiv:1308.1239.

${ }^{10} \mathrm{~J}$. Watanabe, M. Touge, and T. Sakamoto, "Ultraviolet-irradiated precision polishing of diamond and its related materials," Diam. Relat. Mater. 39, 14-19 (2013).

${ }^{11}$ M. Naamoun, A. Tallaire, P. Doppelt, A. Gicquel, M. Legros, J. Barjon, and J. Achard, "Reduction of dislocation densities in single crystal CVD diamond by using self-assembled metallic masks," Diam. Relat. Mater. 58, 62-68 (2015).

${ }^{12}$ P. N. Volpe, P. Muret, F. Omnes, J. Achard, F. Silva, O. Brinza, and A. Gicquel, "Defect analysis and excitons diffusion in undoped homoepitaxial diamond films after polishing and oxygen plasma etching," Diam. Relat. Mater. 18, 1205-1210 (2009).

${ }^{13}$ A. B. Muchnikov, A. L. Vikharev, J. E. Butler, V. V. Chernov, V. A. Isaev, S. A. Bogdanov, A. I. Okhapkin, P. A. Yunin, and Y. N. Drozdov, "Homoepitaxial growth of CVD diamond after ICP pretreatment," Phys. Status Solidi A 212, 2572-2577 (2015).

${ }^{14}$ T. Izak, A. Kromka, O. Babchenko, M. Ledinsky, K. Hruska, and E. Verveniotis, "Comparative study on dry etching of polycrystalline diamond thin films," Vacuum 86, 799-802 (2012).

${ }^{15}$ P. W. Leech, G. K. Reeves, and A. Holland, "Reactive ion etching of diamond in $\mathrm{CF}_{4}, \mathrm{O}_{2}, \mathrm{O}_{2}$ and Ar-based mixtures," J. Mater. Sci. 36, 3453-3459 (2001).

${ }^{16}$ D. S. Hwang, T. Saito, and N. Fujimori, "New etching process for device fabrication using diamond," Diam. Relat. Mater. 13, 2207-2210 (2004).

${ }^{17}$ J. Enlund, J. Isberg, M. Karlsson, F. Nikolajeff, J. Olsson, and D. J. Twitchen, "Anisotropic dry etching of boron doped single crystal CVD diamond," Carbon 43, 1839-1842 (2005).

${ }^{18}$ Y. Ando, Y. Nishibayashi, K. Kobashi, T. Hirao, and K. Oura, "Smooth and high-rate reactive ion etching of diamond," Diam. Relat. Mater. 11, 824-827 (2002).

${ }^{19}$ C. L. Lee, H. W. Choi, E. Gu, M. D. Dawson, and H. Murphy, "Fabrication and characterization of diamond micro-optics," Diam. Relat. Mater. 15, 725-728 (2006).

${ }^{20}$ H. W. Choi, E. Gu, C. Liu, C. Griffin, J. M. Girkin, I. M. Watson, and M. D. Dawson, "Fabrication of natural diamond microlenses by plasma etching," J. Vac. Sci. Technol. B 23, 130 (2005).

${ }^{\mathbf{2 1}}$ K. G. Crawford, A. Tallaire, X. Li, D. A. Macdonald, D. Qi, and D. A. Moran, "The role of hydrogen plasma power on surface roughness and carrier transport in transfer-doped H-diamond," Diam. Relat. Mater. 84, 48-54 (2018).

${ }^{22}$ C. Tavares, S. Koizumi, and H. Kanda, "Effects of RIE treatments for $\{111\}$ diamond substrates on the growth of P-doped diamond thin films," Phys. Status Solidi A 202, 2129-2133 (2005).

${ }^{23}$ E. K. Sanchez, S. Ha, J. Grim, M. Skowronski, W. M. Vetter, and M. Dudley, "Assessment of polishing-related surface damage in silicon carbide," J. Electrochem. Soc. 149, G131-G136 (2002).

${ }^{24}$ D. T. Tran, T. A. Grotjohn, D. K. Reinhard, and J. Asmussen, "Microwave plasma-assisted etching of diamond," Diam. Relat. Mater. 17, 717-721 (2008).

${ }^{25}$ G. Bogdan, M. Nesládek, J. D. Haen, J. Maes, V. V. Moshchalkov, K. Haenen, and M. DÓlieslaeger, "Growth and characterization of near-atomically flat, thick 
homoepitaxial CVD diamond films," Phys. Status Solidi A 202, 2066-2072 (2005).

${ }^{\mathbf{2 6}}$ J. Achard, F. Silva, O. Brinza, X. Bonnin, V. Mille, R. Issaoui, M. Kasu, and A. Gicquel, "Identification of etch-pit crystallographic faces induced on diamond surface by $\mathrm{H}_{2} / \mathrm{O}_{2}$ etching plasma treatment," Phys. Status Solidi A 206, 1949-1954 (2009).

${ }^{27}$ R. Ramesham, W. Welch, W. Neely, M. Rose, and R. Askew, "Plasma etching and patterning of CVD diamond at $<100 \mathrm{C}$ for microelectronics applications," Thin Solid Films 304, 245-251 (1997).
${ }^{28}$ O. Ivanov, A. Muchnikov, V. Chernov, S. Bogdanov, A. Vikharev, and J. Butler, "Experimental study of hydrogen plasma etching of (100) single crystal diamond in a MPACVD reactor," Mater. Lett. 151, 115-118 (2015).

${ }^{29}$ N. Tsubouchi, Y. Mokuno, and S. Shikata, "Characterizations of etch pits formed on single crystal diamond surface using oxygen/hydrogen plasma surface treatment," Diam. Relat. Mater. 63, 43-46 (2016).

${ }^{30} \mathrm{R}$. Edgington, "Diamond and the brain-machine interface," Ph.D. thesis (University College London, UK, 2012). 